\title{
ESTIMATIVA DA EVAPOTRANSPIRAÇÃO EM ÁREA URBANA ATRAVÉS DE IMAGENS DIGITAIS TM - LANDSAT 5
}

\author{
Elvis Bergue Mariz Moreira ${ }^{1}$ \\ Ranyére Silva Nóbrega ${ }^{2}$ \\ Bernardo Barbosa da Silva ${ }^{3}$ \\ Eberson Pessoa Ribeiro ${ }^{4}$
}

Resumo: A evapotranspiração (ET) exerce grande relevância no arrefecimento da temperatura do ar e contribui com o equilíbrio climático em área urbana. Entretanto, o conhecimento das taxas de ET voltados para esta finalidade apresentam-se limitados no campo da pesquisa. Diante disto, esse trabalho objetivou estimar a evapotranspiração na cidade do Recife-PE, visando analisar as diferenças intraurbanas nos diversos tipos de coberturas. Foram utilizadas seis imagens digitais do sensor TM - Landsat 5 referente à órbita 214 e pontos 65,66 . A densidade dos fluxos de calor sensível, e calor latente foram calculados com base no algoritmo SEBAL (Surface Energy Balance Algorithm for Land). Os resultados encontrados na ET estimada apresentaram-se coerentes quando comparados com os valores obtidos pelo método da FAO-Penman-Monteith, com erros absolutos entre 0,18 e 1,23 $\mathrm{mm} \mathrm{d}^{-1}$, mínimo e máximo respectivamente e média de 0,86 mm $\mathrm{d}^{-1}$. As maiores taxas evapotranspirativas foram encontradas nas unidades de conservação e corpos hídricos entre 5,0 e $6,0 \mathrm{~mm} \mathrm{~d}^{-1}$, aproximadamente, enquanto nas superfícies com intenso adensamento construtivo valores próximos de $1,0 \mathrm{~mm}$ $\mathrm{d}^{-1}$. A metodologia utilizada representou de forma consistente os diversos tipos de coberturas, podendo promover um avanço significativo no monitoramento do clima urbano.

Palavras-chave: Clima urbano. Sensoriamento remoto. Sebal. Urbanização. Áreas verdes.

\section{EVAPOTRANSPIRATION ESTIMATION IN URBAN AREAS THROUGH TM DIGITAL IMAGES - LANDSAT 5}

Abstract: Evapotranspiration (ET) has great relevance in the air temperature and contributes to the climate balance in urban areas. In this context, this study aimed to estimate evapotranspiration in the city of Recife-PE in order to analyze the intraurban differences in the various types of roofing. Six digital images of the TM Landsat 5 sensor regarding orbit 214 and points 65,66 were used. The density of sensible heat and latent heat fluxes were calculated based on SEBAL algorithm. The evapotranspiration results were consistent when compared with values obtained by the method of FAO-Penman-Monteith, with absolute error between 0.18 and 1.23 $\mathrm{mm} \mathrm{d} \mathrm{d}^{-1}$, minimum and maximum, respectively, and average of $0.86 \mathrm{~mm} \mathrm{~d}^{-1}$. The highest evapotranspiration rates were found in protection units and water bodies between 5.0 and $6.0 \mathrm{~mm} \mathrm{~d}^{-1}$, approximately, while in surfaces with intense constructive densification, values close to $1.0 \mathrm{~mm} \mathrm{~d}^{-1}$ were found. The methodology

\footnotetext{
${ }^{1}$ Universidade Federal do Oeste da Bahia (UFOB), Centro das Humanidades, Barreiras-BA, Brasil, elvis.moreira@ufob.edu.br, https://orcid.org/0000-0001-6732-3005

${ }^{2}$ Universidade Federal de Pernambuco (UFPE), Departamento de Ciências Geográficas, Recife-PE, Brasil, rs_nobrega@yahoo.com.br, https://orcid.org/0000-0001-9097-1537

${ }^{3}$ Universidade Federal de Campina Grande (UFCG), Departamento de Ciências Atmosféricas, Campina Grande-PB, Brasil, bernardo.silva@ufcg.edu.br, https://orcid.org/0000-0003-2500-1547

${ }^{4}$ Instituto Federal de Educação, Ciência e Tecnologia de Pernambuco (IFPE), Departamento Acadêmico de Ambiente, Saúde e Segurança (DASS), Recife-PE, Brasil, ebersonpessoa@recife.ifpe.edu.br, https://orcid.org/0000-0001-8316-6505
} 
used consistently represented the various types of roofing and can promote a significant advance in the monitoring of the urban climate.

Keywords: Urban climate. Remote sensing. Sebal. Urbanization. Green areas.

\section{ESTIMATIVA DE LA EVAPOTRANSPIRACIÓN EN ÁREA URBANA A TRAVÉS DE IMÁGENES DIGITALES TM - LANDSAT 5}

Resumen: La evapotranspiración (ET) ejerce gran relevancia en el enfriamiento de la temperatura del aire y contribuye con el equilibrio climático en el área urbana. Sin embargo, el conocimiento de las tasas de ET dirigidas a este propósito se presentan limitadas en el campo de la investigación. En este sentido, este trabajo objetivó estimar la evapotranspiración en la ciudad de Recife-PE, buscando analizar las diferencias intraurbanas en los diversos tipos de coberturas. Se utilizaron seis imágenes digitales del sensor TM - Landsat 5 referente a la órbita 214 y puntos 65, 66 . La densidad de los flujos de calor sensibles, y el calor latente, se calcularon sobre la base del algoritmo SEBAL (Surface Energy Balance Algorithm for Land). Los resultados encontrados en la ET estimada se presentaron coherentes cuando se compararon con los valores obtenidos por el método de la FAO-Penman-Monteith, con errores absolutos entre 0,18 y $1,23 \mathrm{~mm} \mathrm{~d}^{-1}$, mínimo y máximo respectivamente y promedio de $0,86 \mathrm{~mm} \mathrm{~d}^{-1}$. Las mayores tasas de evapotranspiración se hallaron en las unidades de conservación y los cuerpos hídricos entre 5,0 y 6,0 mm d-1, aproximadamente, mientras que en las superficies con intenso adensamiento constructivo valores cercanos a $1,0 \mathrm{~mm} \mathrm{~d}^{-1}$. La metodología utilizada representó de forma consistente los diversos tipos de coberturas, pudiendo promover un avance significativo en el monitoreo del clima urbano.

Palabras clave: Clima urbano. Detección remota. Sebal. Urbanización. Áreas verdes.

\section{Introdução}

Nas últimas décadas o clima das áreas urbanas vem sendo objeto de estudos em todo o mundo, sobretudo com o atual enfoque das mudanças climáticas e as elevadas taxas de crescimento populacional evidenciada nas grandes cidades. $O$ reflexo do referido crescimento imprime uma nova conotação no uso do solo, proporcionando progressiva deterioração dos ambientes urbanos e periurbanos, especificamente impulsionado pelas pressões econômicas e especulativas nas grandes cidades, refletindo na substituição de áreas verdes por ambientes artificiais proporcionando uma dependência crescente por materiais de construção civil (LOMBARDO, 1985).

O adensamento construtivo atrelado às pressões econômicas no uso do solo demanda o surgimento de novas feições impermeáveis com características que facilitam a absorção de calor e proporcionam alterações significantes no balanço de energia e taxas evaporativas. Monteiro (1990) sinaliza que os espaços urbanos passaram a assumir a responsabilidade do impacto máximo da atuação humana 
sobre a organização na superfície terrestre e na deterioração do ambiente, seja pela implosão demográfica e/ou pela explosão das atividades.

O clima urbano altera as trocas de energia entre a interface superfície-atmosfera, favorecendo um maior percentual de energia disponível a ser empregada no aquecimento da superfície, proporcionando desta forma o aumento da temperatura do ar, colaborando com a redução das taxas evaporativas e aumento de zonas quentes (GRIMMOND et al., 2007). Conforme Monteiro (1990), os condicionantes geoambientais representados pelos elementos naturais presentes em uma área urbana, destacando-se as áreas verdes, corpos hídricos e relevo, assim como os geourbanos compreendendo a densidade da área construída, alta dos edifícios, orientação e largura das ruas, devem ser considerados em análises de balanço em áreas urbanas.

A evapotranspiração é responsável por quase todo o volume de água transferido dos continentes para a atmosfera, além de desempenhar um papel de suma importância na liberação de calor latente, que de acordo com Bastiaanssen et al. (1998), o seu valor integrado no tempo é importante para diferentes aplicações em estudos de modelagem e monitoramento do clima.

De acordo com Chandler (1976) a maioria dos estudos apontam que o percentual de áreas verdes nas áreas urbanas por ser inferior a zonas rurais circunvizinhas reflete nos contrastes das propriedades hidrológicas devido ao intenso uso da superfície com materiais impermeáveis. No entanto, em muitas áreas urbanas os percentuais de superfícies vegetadas cobrem áreas significativas, chegando apresentar um número de árvores superior ao comparado com a paisagem rural circundante, consequentemente apresentam alto potencial na produção de umidade por advecção e evapotranspiração em micro escala.

Diversas pesquisas têm feito o uso da evapotranspiração para determinar a perda de água em áreas de agricultura irrigada e bacias hidrográficas com atenções direcionadas para o monitoramento e gerenciamento. Em superfícies urbanas os estudos relacionados a evapotranspiração são limitados, em particular, os voltados com enfoque climático, considerando que os equipamentos utilizados na mensuração não são de fácil acesso, apresentam altos custos e não contemplam a representação dos distintos tipos de cobertura. Sendo assim, o sensoriamento remoto tem se mostrado uma abordagem adequada para estimativa da evapotranspiração em grandes áreas, pois satélites são capazes de fornecer parâmetros representativos, como características radiométricas da superfície, albedo e índices de vegetação consistentes, de maneira prática e economicamente viável. A exemplo da ET estimada via imagens orbitais, 
destaca-se o algoritmo SEBAL, que requer apenas de imagens de satélite e dados medidos em estações meteorológicas (CHOUDHURY 1989; KUSTAS; NORMAN, 1996).

A vegetação e os corpos hídricos exercem grande relevância no balanço de energia em áreas urbanas, proporcionando transporte continuo de umidade para atmosfera oriundas da evapotranspiração e evaporação, ocasionado pelo fluxo de calor latente (LE). Silva et al. (2010) apontam que o fluxo de calor latente representa o fluxo de massa na forma de vapor de água para atmosfera do nosso planeta. Em superfícies urbanas o mesmo apresenta-se com índices inferiores ao comparado em áreas rurais, entretanto destaca-se em grande relevância para o equilíbrio do clima na escala intraurbana através do potencial em criar zonas produtoras de umidade para um ambiente natural, proporcionando menores temperaturas ao comparado com as áreas adjacentes desprovidas de vegetação e corpos hídricos (PEREZ et al., 2001).

O SEBAL (Surface Energy Balance for Land) possibilita estimar e representar espacialmente a evapotranspiração, utilizando poucos dados de superfície, o que o faz o mais utilizado na atualidade em diversas regiões do mundo (BASTIAANSSEN et al., 1998; BASTIAANSSEN, 2000; TASUMI, 2003; SILVA; BEZERRA, 2006; BEZERRA et al., 2008; TEIXEIRA et al., 2009a,b; MOREIRA, 2014). Diante da importância do conhecimento de informações disponíveis do clima de uma cidade assim como sua relevante contribuição ao planejamento urbano, esse trabalho objetiva estimar a evapotranspiração na cidade do Recife-PE, se utilizado do algoritmo SEBAL e imagens multiespectrais do TM Landsat 5.

\section{Materiais e métodos}

\section{Área de estudo}

O objeto do estudo é a cidade do Recife (Figura 1) capital do estado de Pernambuco, localizada no litoral do Nordeste brasileiro na porção centro leste da região, compreendendo uma área territorial de $217,494 \mathrm{~km}^{2}$, limitando-se, ao norte, com as cidades de Olinda e Paulista, ao sul com o município de Jaboatão dos Guararapes, à oeste com São Lourenço da Mata e Camaragibe e à leste com o Oceano Atlântico. 
O clima da cidade é caracterizado por ser quente e úmido As' com chuvas de outono a inverno, iniciadas nos meses de março e isotermas que variam entre $26^{\circ} \mathrm{C}$ e 22 ${ }^{\circ} \mathrm{C}$, apresentando elevada umidade relativa do ar, com valores médios anuais superiores $84 \%$, de acordo com a classificação de Köppen. A região estudada está situada dentro da Zona Intertropical, e com latitude próximo ao Equador, apresenta alta taxa de isolação em virtude de receber os raios solares de forma perpendicular em sua superfície e altos índices de insolação, praticamente constantes entre os meses de verão (maior insolação) e inverno (menor insolação). Assim, apresenta temperatura do ar média mensal em torno de $25^{\circ} \mathrm{C}$, sendo os meses de janeiro e fevereiro os mais quentes, com temperaturas superiores a $26{ }^{\circ} \mathrm{C}$, enquanto os meses de julho e agosto apresentam temperaturas iguais ou inferiores a $24^{\circ} \mathrm{C}$, constituindo-se os mais frios, registrando uma diferença anual de apenas $3{ }^{\circ} \mathrm{C}$ entre janeiro e julho e com amplitude térmica diária podendo chegar $>6$ ${ }^{\circ} \mathrm{C}$ (CORREA, 2006).

As unidades de conservação e áreas vegetadas são representadas na cor em verde, com maior expressão na região norte e oeste, setor conhecido como cinturão verde da cidade, localizadas nas áreas de proteção ambiental e reservas ecológicas, caracterizados por fragmentos de mata atlântica e Manguezal na região sul.

O sistema fluvial da cidade está incluindo o rio Capibaribe e outros corpos hídricos, está representado na cor em azul escuro. A tonalidade rosa na imagem compreende 0 setor onde está situada a malha urbana, com enfoque aos loteamentos formais localizados na área de intensa urbanização e em maior magnitude na cidade. Conforme as feições representadas, assegura-se que a mancha urbana se apresenta com solo bastante influenciado por pressões econômicas, destacando-se com elevado grau de adensamento construtivo e superfícies impermeáveis. 


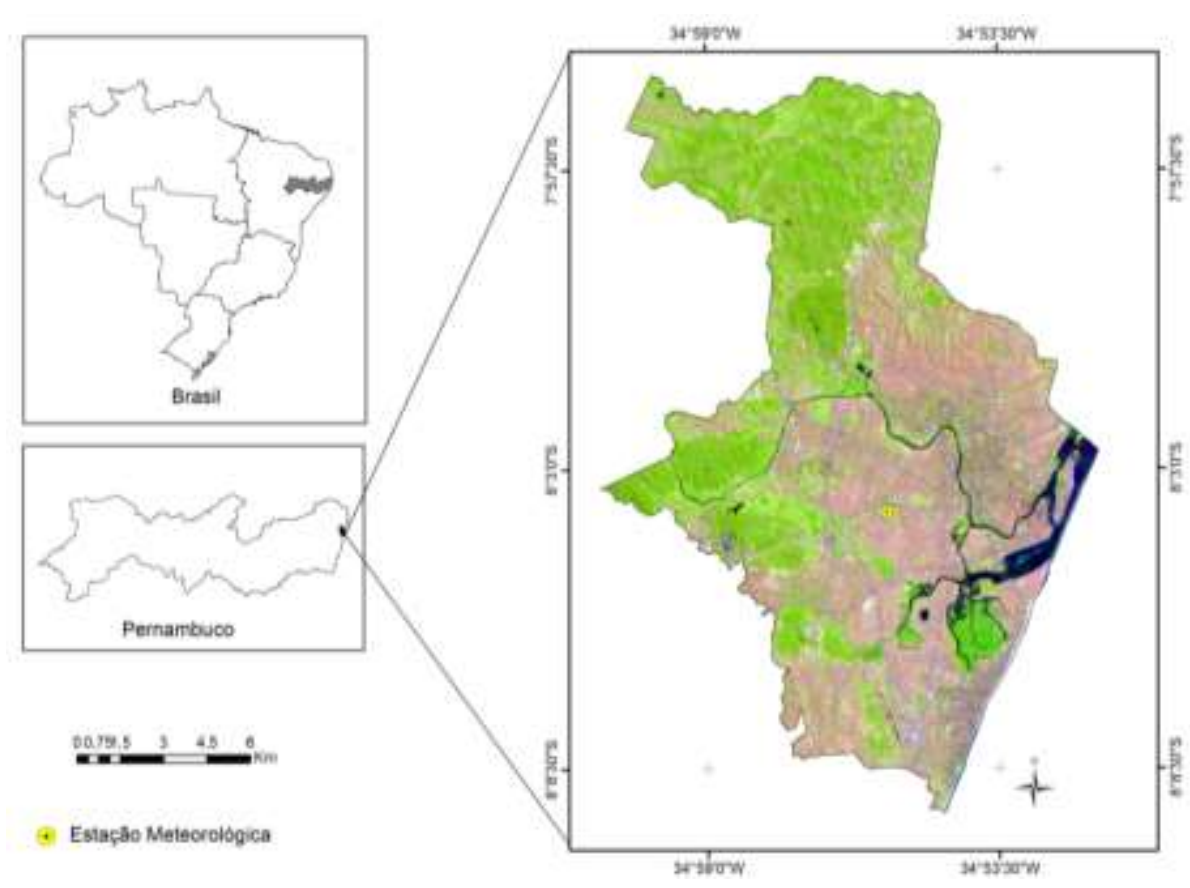

Figura 1. Localização da área objeto do estudo. Mapa do Brasil, mapa de Pernambuco e imagem do TM Landsat 5 destacando a cidade do Recife na composição $R(5), G(4), B(3)$.

\section{Dados orbitais}

Foram utilizadas seis imagens digitais geradas pelo sensor Mapeador Temático (Thematic Mapper - TM), abordo do satélite Landsat 5, características apresentadas na Tabela 1. As cenas foram obtidas no site de geração de imagens do Instituto Nacional de Pesquisas Espaciais. O recorte da cidade do Recife compreende duas imagens referentes a órbita 214 e pontos de recobrimento da área 65 e 66, com datas e parâmetros de calibração. Foram empilhadas bandas à banda e posteriormente registradas pela correção geométrica polinomial de primeira ordem, com três pontos de controle possibilitando um erro inferior a um pixel, tomando por base uma imagem registrada. No segundo momento foi realizado o mosaico e a exclusão dos números digitais referentes a nuvens e sombras de nuvens através da realização de uma classificação supervisionada.

O MDE (Modelo Digital de Elevação) da área em estudo foi adquirido junto ao site da Embrapa Monitoramento por Satélite (Brasil Relevo) no produto SRTM (Shuttle Radar Topography Mission) referente aos mosaicos SB-25-Y-C e SC-25V-A. As imagens foram reamostradas de sua resolução original $90 \times 90 \mathrm{~m}$ para $30 \times 30 \mathrm{~m}$, sendo utilizada como base no cômputo da transmitância instantânea e pressão atmosférica em cada pixel. 
Tabela 1. Descrição das bandas e faixas espectrais correspondentes ao TM Landsat 5, coeficientes de calibração mínimo (a) e máximo (b), irradiância solar espectral $(K \lambda)$ no topo da atmosfera (TOA).

\begin{tabular}{|c|c|c|c|c|c|c|c|c|c|}
\hline \multirow{3}{*}{ Bandas } & \multicolumn{7}{|c|}{$\begin{array}{l}\text { Coeficientes de Calibração } \\
\left(\mathrm{Wm}^{-2} \mu \mathrm{m}^{-1}\right)\end{array}$} & & \\
\hline & \multirow{2}{*}{$\begin{array}{c}\text { Faixa } \\
\text { espectral } \\
(\mu \mathrm{m})\end{array}$} & \multicolumn{2}{|c|}{$\begin{array}{l}01 / 03 / 1984 \\
\text { até } 04 / 05 / 2003\end{array}$} & \multicolumn{2}{|c|}{$\begin{array}{l}05 / 05 / 2003 \\
\text { até 01/04/2007 }\end{array}$} & \multicolumn{2}{|c|}{$\begin{array}{c}\text { Após } \\
02 / 04 / 2007\end{array}$} & \multicolumn{2}{|c|}{$\begin{array}{c}K_{\lambda}\left(\lambda_{i}\right) \\
\left(W^{-2} \mu m^{-1}\right)\end{array}$} \\
\hline & & a & b & a & b & a & b & & \\
\hline 1 (azul) & $0,45-0,52$ & $-1,52$ & 152,10 & $-1,52$ & 193,00 & $-1,52$ & 169,00 & 1957 & 0,93 \\
\hline 2 (verde) & $0,52-0,60$ & $-2,84$ & 296,81 & $-2,84$ & 365,00 & $-2,84$ & 333,00 & 1826 & 0,274 \\
\hline 3 (vermelho) & $0,63-0,69$ & $-1,17$ & 204,30 & $-1,17$ & 264,00 & $-1,17$ & 264,00 & 1554 & 0,233 \\
\hline 4 (IV-próximo) & $0,76-0,90$ & $-1,51$ & 206,20 & $-1,51$ & 221,00 & $-1,51$ & 221,00 & 1036 & 0,155 \\
\hline 5 (IV-médio) & $1,55-1,75$ & $-0,37$ & 27,19 & $-0,37$ & 30,20 & $-0,37$ & 30,2 & 215,0 & 0,032 \\
\hline 6 (IV-termal) & $10,4-12,5$ & 1,2378 & 15,303 & 1,2378 & 15,303 & 1,2378 & 5,03 & 3 & 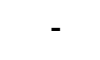 \\
\hline 7 (IV-médio) & $2,10-2,35$ & $-0,15$ & 14,38 & $-0,15$ & 16,50 & $-0,15$ & 16,50 & 80,67 & 0,012 \\
\hline
\end{tabular}

Fonte: Adaptado de Chander et al. (2007).

\section{Dados micrometeorológicos}

Os dados micrometeorológicos complementares utilizados para implementação do modelo SEBAL: velocidade do vento, temperatura do ar no instante da passagem do satélite, temperatura máxima, temperatura mínima, radiação solar global diária, além da umidade relativa do ar, máxima e mínima, e pressão atmosférica para estimativa da transmissividade atmosférica e dados de precipitação, foram obtidas na PCD (Plataforma de coleta de dados automática) pertencente ao SINDA (Sistema Nacional de Dados Ambientais) localizada na latitude $-8,05000^{\circ}$ e longitude $-34,9500^{\circ}$ e altitude 10,0 metros, situada dentro do IPA (Instituto Agronômico de Pernambuco) (Tabela 2).

Tabela 2. Parâmetros utilizados na calibração e no cômputo do balanço de radiação, balanço de energia e seus componentes, obtidos das imagens e da estação meteorológica automática (PCD Recife).

\begin{tabular}{ccccc}
\hline DAS & 269 & 238 & 249 & 268 \\
Data da Imagem & $26 / 09 / 2000$ & $26 / 08 / 2006$ & $06 / 09 / 2010$ & $25 / 09 / 2011$ \\
\hline $\mathrm{E}\left({ }^{\circ}\right)$ & 58,2887 & 55,6194 & 56,6385 & 60,4358 \\
Cos Z & 0,8507 & 0,8253 & 0,8352 & 0,8698 \\
Hora Passagem & $12: 07: 49$ & $12: 22: 36$ & $12: 19: 42$ & $12: 17: 46$ \\
dr & 0,9973 & 0,9809 & 0,9864 & 0,9967 \\
$T_{\text {ar }}\left(^{\circ} \mathrm{C}\right)$ & 25,0 & 24,5 & 21,0 & 22,5 \\
$T_{\text {ar }} \min \left({ }^{\circ} \mathrm{C}\right)$ & 23,5 & 24,0 & 20,0 & 21,5 \\
$T_{\text {ar }} \max \left({ }^{\circ} \mathrm{C}\right)$ & 30,0 & 29,5 & 30,0 & 31,0 \\
UR\% & 80 & 100 & 88 & 90 \\
UR\% min & 75 & 65 & 70 & 75 \\
UR $\% \max$ & 90 & 95 & 90 & 98 \\
\hline
\end{tabular}




$\begin{array}{ccccc}\operatorname{Par}(\mathrm{kPa}) & 101,3 & 101,0 & 101,7 & 101,5 \\ \mathrm{U}^{*}\left(\mathrm{~m}^{-1}\right) & 2,6 & 2,0 & 1,5 & 10,8 \\ \operatorname{Rs} 24 \mathrm{~h}\left(\mathrm{MJ} \mathrm{m}^{-2}\right) & 26,1 & 22,5 & 25,1 & 23,9\end{array}$

DSA: Dia Sequencial do Ano; $E\left(^{\circ}\right)$ = Ângulo de elevação solar, $\cos Z$ = Cosseno do ângulo zenital solar, Hora: (Tempo Central GMT), dr: Inverso do quadrado da distância relativa Terra-Sol; Tar $\left({ }^{\circ} \mathrm{C}\right)$ : Temperatura do ar; $\operatorname{Tar} \min \left({ }^{\circ} \mathrm{C}\right)$ : Temperatura mínima do ar; Tar,max $\left({ }^{\circ} \mathrm{C}\right)$ : Temperatura máxima do ar; UR \%: Umidade relativa do ar; UR\% min: Umidade relativa do ar mínima; UR\% max: Umidade relativa do ar máxima; Par (kPa): Pressão atmosférica em Quilo Pascal; $U^{*}(\mathrm{~m} . \mathrm{s}-1)$ : Velocidade do vento a 10m; Rs 24h (MJ m-2): Radiação solar diária obtida através do piranômetro licor.

As datas das imagens 26/09/2000 (DSA 269), 26/08/2006 (DSA 238), 06/09/2010 (DSA 249) e 25/09/2011 (DSA 268) apresentam dados de épocas semelhantes, referentes às estações do inverno. No instante da passagem do satélite nas referidas datas não houve eventos de chuva, apenas foi registrado nos três dias anteriores, conforme representados na Figura 2.

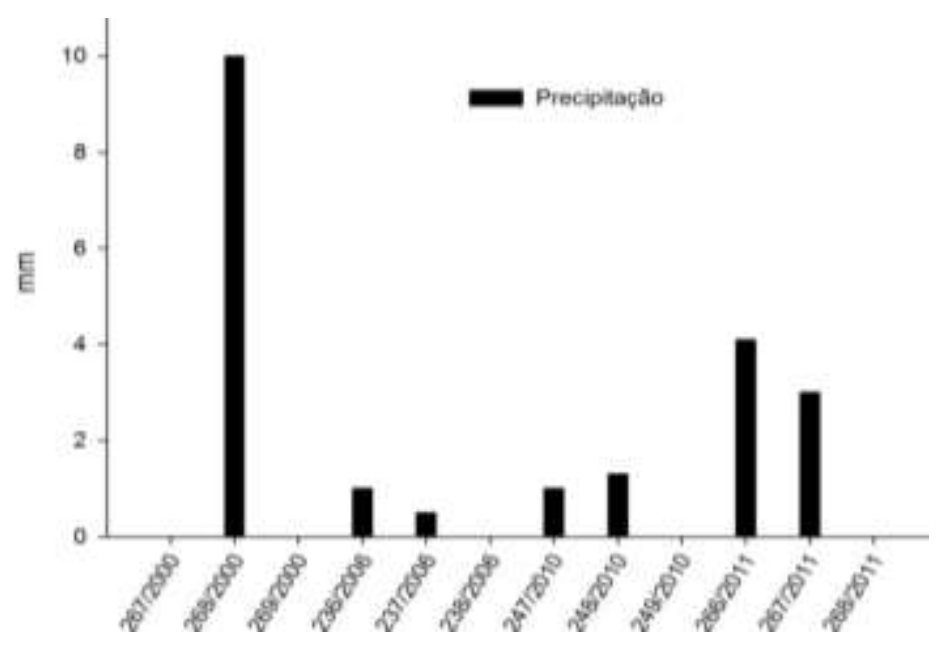

Figura 2. Precipitação acumulada nos três anterior a passagem do satélite.

\section{Processamento das imagens}

$\mathrm{Na}$ fase do processamento das imagens de satélite e cômputo dos parâmetros do balanço de energia como também na montagem final do layout e geração dos mapas utilizou-se o software Erdas Imagine versão 9.3 executado a ferramenta Model Maker e o ArcGis versão 10.1. Os valores estatísticos das imagens foram obtidos através da conversão para o formato ASCII usadas para geração de tabelas que posteriormente foram representadas em gráficos processados no programa SigmaPlot 10.0 . 
O algoritmo SEBAL, é um método que objetiva a estimativa instantânea dos componentes do balanço de energia por sensoriamento remoto, possibilitando também o cômputo da evapotranspiração (Etr) e tendo como base combinações empíricas (emissividade e temperatura da superfície, emissividade da atmosfera, fluxo de calor no solo e comprimento de rugosidade aerodinâmica para o transporte de momentum e parametrizações físicas, constituindo-se em trinta e quatro etapas para seu processamento (BASTIAANSSEN et al., 1998). Os pilares do algoritmo são sustentados com imagens de satélite além de outras informações usualmente obtidas em estações meteorológicas de superfície (ALLEN et al., 2002; SILVA e BEZERRA, 2006; BEZERRA et al., 2008; MOREIRA et al., 2014).

A exatidão do modelo SEBAL muda com o grau de heterogeneidade da superfície e com o tamanho do pixel (MEDINA et al., 1998; BASTIAANSSEN et al., 1998; TIMMERMANS et al., 2011). Portanto em áreas urbanas é crucial a existência de corpos hídricos na seleção do pixel frio (âncora) possibilitando assim alta amplitude com o pixel quente (âncora) e, que a feição seja contemplada pela resolução espacial do satélite. No trabalho em análise, a seleção dos pixels supracitados foi realizada com base na carta de temperatura da superfície, onde o pixel frio situou-se dentro do Manguezal (superfície com água), enquanto o pixel quente foi representado no Shopping Center Recife (superfície impermeável).

O algoritmo SEBAL possibilitou realizar o computo da densidade dos fluxos de radiação, sendo a evapotranspiração calculada após a conversão do valor instantâneo do fluxo de calor latente LE (W m²), em ET (mm) 24h. O LE foi obtido como resíduo da equação clássica do balanço de energia à superfície:

$$
\mathrm{LE}=\mathrm{Rn}-\mathrm{G}-\mathrm{H}
$$

onde $\mathrm{Rn}$ é o saldo de radiação, LE é a densidade de fluxo de calor latente, $\mathrm{H}$ é a densidade de fluxo de calor sensível e G é a densidade de fluxo de calor no solo, ambos com unidade $\left(\mathrm{W} \mathrm{m}^{-2}\right)$. Rn é uma variável fundamental para o cômputo do balanço de energia e que envolve a calibração radiométrica, cálculo da reflectância, albedo, índices de vegetação, emissividade e temperatura da superfície (SILVA et al., 2011), sendo calculado através da seguinte equação:

$$
\mathrm{Rn}=\mathrm{R}_{\mathrm{S} \downarrow}(1-\lambda)+\mathrm{R}_{\mathrm{L} \downarrow}-\mathrm{R}_{\mathrm{L} \uparrow}-\left(1-\varepsilon_{0}\right) \mathrm{R}_{\mathrm{L} \downarrow}
$$


em que $R_{S \downarrow}$ é a radiação de onda curta incidente em cada pixel, $\lambda$ é o albedo corrigido de cada pixel, $\mathrm{R}_{\mathrm{L} \downarrow}$ é a radiação de onda longa emitida da atmosfera para superfície, $\mathrm{R}_{\mathrm{L} \uparrow}$ é a radiação de onda longa emitida por cada pixel e $\varepsilon_{0}$ é a emissividade de cada pixel da cena estudada.

O fluxo de calor constitui-se na segunda dos três componentes do balanço de energia a ser estimado. Para tanto, se usa o saldo de radiação instantâneo estimado (Rn) na etapa anterior e uma relação empírica desenvolvida por Bastiaanssen (2000), que representa valores próximos ao meio-dia:

$\mathrm{G}=\mathrm{T}_{\mathrm{S}} / \alpha\left(0,0038 \cdot \alpha+0.0074 \cdot \alpha^{2}\right)\left(1-0,98 \mathrm{NDVI}^{4}\right) \mathrm{Rn}$

em que: Ts é a temperatura da superfície $\left({ }^{\circ} \mathrm{C}\right)$, $\alpha$ é o albedo da superfície e NDVI (Índice de Vegetação da Diferença Normalizada), definido pela razão da diferença pela soma das reflectividades dos canais do infravermelho próximo ( $\rho_{\text {iv }}$ ) e vermelho $\left(\rho_{v}\right)$ (PONZONI; SHIMABUKURO, 2007).

A estimativa do fluxo de calor sensível $\mathrm{H}\left(\mathrm{W} \mathrm{m}^{-2}\right)$ foi obtido com base na velocidade do vento e na temperatura da superfície, usando uma calibração interna da diferença da temperatura entre dois níveis da superfície, segundo Bastiaanssen et al. (1998), conforme equação:

$$
\mathrm{H}=\rho \cdot \mathrm{c}_{\rho} \cdot \frac{\mathrm{dT}}{\mathrm{r}_{\mathrm{a}}}
$$

onde $\rho$ é a densidade do $\operatorname{ar}\left(\mathrm{kg} \mathrm{m}^{-3}\right), \mathrm{c}_{\mathrm{p}}$ é o calor específico do $\operatorname{ar}\left(1004 \mathrm{Jkg}^{-1} \mathrm{~K}^{-1}\right)$, dT (K) é a diferença de temperatura entre a superfície e um nível de referência e ra é a resistência aerodinâmica ao transporte de calor $\left(\mathrm{sm}^{-1}\right)$, sendo $\circ \mathrm{H}$ função do gradiente vertical de temperatura, rugosidade da superfície e velocidade do vento. Para a sua obtenção faz-se necessário o conhecimento da velocidade do vento e na sequência a resistência aerodinâmica ao transporte de calor $r_{a}$ e valores de $R n$ e $G$ em dois pixels âncoras, através dos quais será possível determinar a variação de temperatura (dT). A Figura 3 está representada no fluxograma do processo iterativo para obtenção do fluxo de calor sensível $(\mathrm{H})$.

Inicialmente, é determinada a velocidade de fricção $\mathrm{u}^{*}\left(\mathrm{~m} \mathrm{~s}^{-1}\right)$, calculada usandose o perfil logarítmico do vento em atmosfera com equilíbrio neutro, através da equação: 


$$
\mathrm{u}_{8}=\frac{\mathrm{ku}_{\mathrm{x}}}{\ln \left(\frac{\mathrm{z}_{\mathrm{x}}}{\mathrm{z}_{0 \mathrm{~m}}}\right)}
$$

onde: $\mathrm{k}$ é constante de Von Karman = 0,41 (FILHO et al., 1992), Ux é a velocidade do vento na altura $\mathrm{z}_{\mathrm{x}}, \mathrm{z}_{0 \mathrm{~m}}$ é o coeficiente de rugosidade para o transporte de momentum $(\mathrm{m})$, obtido através da altura $(\mathrm{h})$ da vegetação média existente no entorno da estação meteorológica, que segundo Brutsaert (1982) =0,12 h.

Considerando a atmosfera em equilíbrio neutro e o perfil logaritmo do vento projetou-se a velocidade do vento a um nível $Z$, onde a mesma não é a afetada pela rugosidade da superfície, altura essa denominada de blending height. Para as condições de Recife, foi adotada $Z=200 \mathrm{~m}$, admitindo-se, constante nos demais pixels da imagem. Sendo assim, a velocidade de fricção cada pixel da imagem, é obtida segundo a equação 20 (ALLEN et al., 2002; TREZZA, 2002, SILVA e BEZERRA, 2006).

$$
\mathrm{u}_{8}=\frac{\mathrm{ku}_{200}}{\ln \left(\frac{200}{\mathrm{z}_{0 \mathrm{~m}}}\right)}
$$

em que $u_{200}$ (ms -1) é a velocidade do vento a $200 \mathrm{~m} \mathrm{e} \mathrm{z}_{0 \mathrm{~m}}$ é o coeficiente de rugosidade de cada pixel $(m)$, obtido pixel a pixel em função da imagem do IVAS (Índice de vegetação ajustado ao solo) segundo equação desenvolvida por Bastiaanssen (2000):

$$
\mathrm{Z}_{0 \mathrm{~m}}=\exp (-5,809+5,62 \text { IVAS })
$$




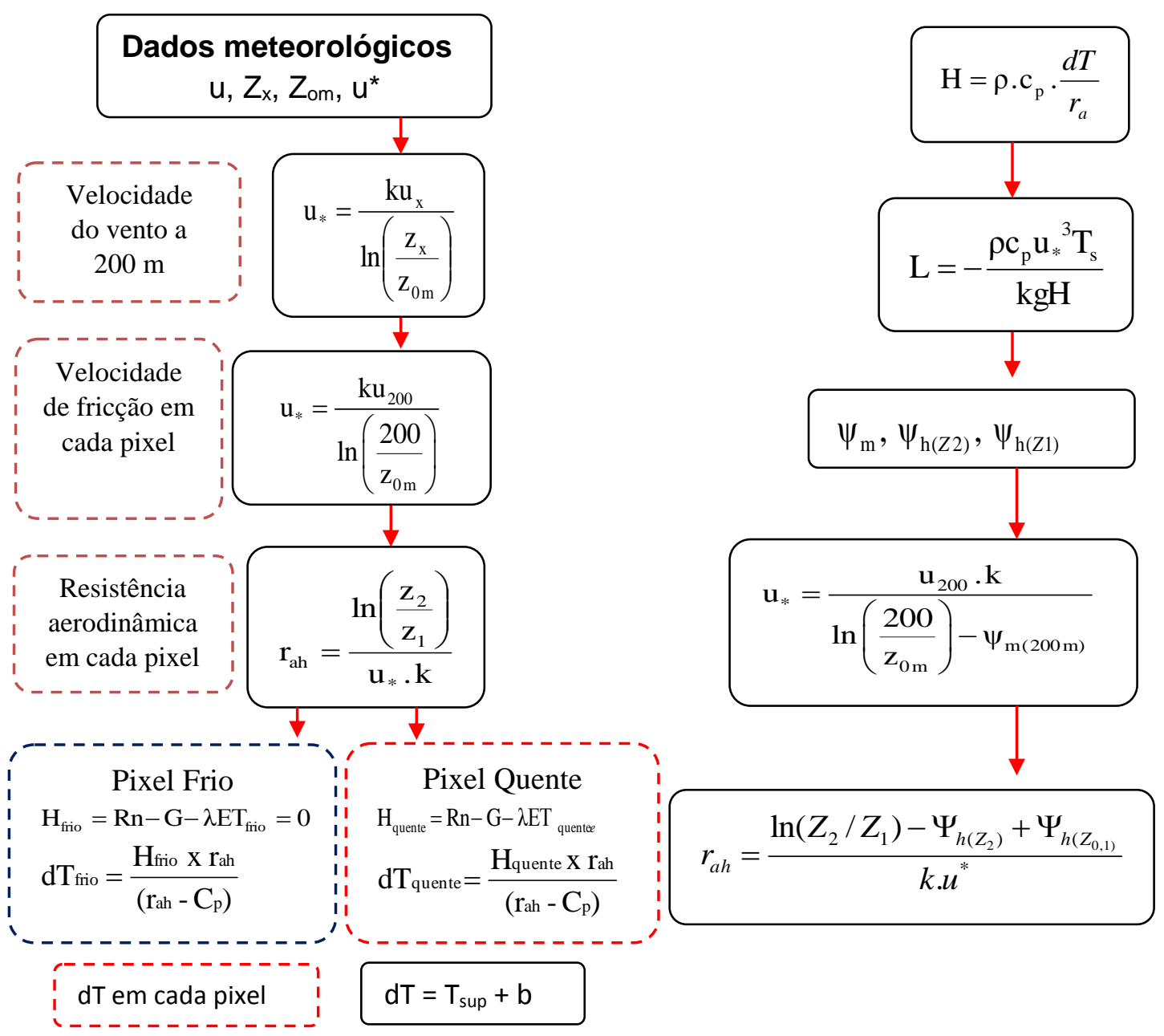

Figura 3. Fluxograma do processo iterativo de Monin Obukov para a estabilização de rah.

Adquirido os valores de para cada pixel, estimou-se a resistência aerodinâmica ao transporte de calor sensível (-rah), admitindo-se também a atmosfera em condições de estabilidade neutra, segundo a equação abaixo (ALLEN et al., 2002; TREZZA, 2002, SILVA e BEZERRA, 2006; MENDONÇA et al., 2012).

$$
\mathrm{r}_{\mathrm{ah}}=\frac{\ln \left(\frac{\mathrm{z}_{2}}{\mathrm{z}_{1}}\right)}{\mathrm{u}_{8} \cdot \mathrm{k}}
$$

onde $Z_{1}$ e $Z_{2}$ são as alturas acima da superfície (em alguns estudos mais recentes têm sido utilizados $0,1 \mathrm{~m}$ e 2,0 $\mathrm{m}$, respectivamente).

Para efetuar o processo iterativo conforme fluxograma supracitado é feito inicialmente a escolha de dois "pixels âncoras" nas cenas estudadas, os quais são caracterizado como pixeis "frio" e "quente" selecionados através do campo de 
temperatura da superfície e que serão utilizados para definir uma relação linear entre a temperatura da superfície (Ts) e a dT, visando estabelecer os valores constantes de calibração de dT (a e b). Diante da carta de temperatura da superfície foi possível realizar a seleção dos pixels supracitados, onde o frio situou-se dentro do Manguezal do Pina (superfície com água), enquanto o pixel quente foi representado no Shopping Center Recife (superfície impermeável). O fluxo de calor sensível $H_{\text {quente }}(\mathrm{W}$ m-2) é dado por:

$\mathrm{H}_{\text {quente }}=\mathrm{R}-\mathrm{G}=\frac{\rho c_{\mathrm{p}}\left(\mathrm{a}+\mathrm{b} \mathrm{T}_{\mathrm{sup}}\right)}{\mathrm{r}_{\mathrm{ahh}}}$

Onde $\rho$ (kg.m-3) é a massa específica do ar, $\mathrm{cp}$ o calor específico a pressão constante $\left(\mathrm{Jkg}^{-1} \mathrm{k}^{-1}\right)$ e Tsup, Rn e G foram obtidos no pixel quente da imagem. Com base nesses valores, obteve-se:

$\mathrm{a}+\mathrm{b} \mathrm{T}_{\mathrm{sup}}=\mathrm{r}_{\mathrm{ah}}\left(\mathrm{R}_{\mathrm{n}}-\mathrm{G}\right) / \rho \mathrm{c}_{\rho}$

Como no pixel frio $d T=0$, ou seja, $a+b T_{\text {gup }}=0$, tem-se um sistema com duas equações e duas incógnitas, o que possibilita o cálculo de a e b. Logo, pode-se obter $\mathrm{H}$, segundo a equação 5 mencionada anteriormente. No entanto, os valores obtidos não representam adequadamente $\mathrm{o} \mathrm{H}$ de cada pixel e servem, tão somente, como valores iniciais de um processo iterativo, e que nas etapas seguintes se considerada, efetivamente, a condição de estabilidade de cada pixel. Dessa forma, dado que os efeitos turbulentos afetarem as condições atmosféricas e a resistência aerodinâmica, aplica-se a teoria da similaridade de Monin-Obukhov (1954), sendo considerada no cômputo do fluxo de calor sensível em todos os pixels da área de estudo, realizada pela seguinte equação:

$\mathrm{L}=-\frac{\rho \mathrm{c}_{\mathrm{p}} \mathrm{u}_{8}{ }^{3} \mathrm{~T}_{\mathrm{sup}}}{\mathrm{KgH}}$

Os valores de $L$ definem as condições de estabilidade da seguinte forma: se $L$ $<0$, a atmosfera é considerada instável; se $L>0$, a atmosfera é considerada estável e se $L=0$ a atmosfera é considerada neutra. Dependendo das condições atmosféricas, os valores das correções de estabilidade para o transporte de momentum e de calor deverão ser considerados. Sendo assim, utiliza-se das formulações de Paulson (1970) e Webb (1970). 
O valor corrigido para a velocidade de fricção é dado por (SILVA e BEZERRA, 2006; BEZERRA et al., 2011):

$$
\mathrm{u}_{*}=\frac{\mathrm{u}_{200} \cdot \mathrm{k}}{\ln \left(\frac{200}{\mathrm{z}_{0 \mathrm{~m}}}\right)-\Psi_{\mathrm{m}(200 \mathrm{~m})}}
$$

onde k é a constante de von Karman $(0,41)$, e $\Psi_{m(200 m)}$ é a correção da estabilidade para o transporte de momentum a $200 \mathrm{~m}$. Tendo obtido $\mathrm{u}_{8}$ corrigido, foi obtido o valor corrigido para a resistência aerodinâmica ao transporte de calor $r_{a h}\left(\mathrm{sm}^{-1}\right)$ através da seguinte equação (SILVA e BEZERRA, 2006; BEZERRA et al., 2011, MENDONÇA et al., 2012):

$\mathrm{r}_{\mathrm{ah}}=\frac{\ln \left(\mathrm{Z}_{\mathrm{z}} / \mathrm{Z}_{1}\right)-\Psi_{\mathrm{h}\left(\mathrm{Z}_{\mathrm{z}}\right)}+\Psi_{\mathrm{h}\left(\mathrm{Z}_{\mathrm{O}, 1)}\right)}}{\mathrm{k.u} *}$

onde $\quad Z_{2}=2,0 \mathrm{~m}, Z_{1}=0,1 \mathrm{~m}$, e $\Psi_{\mathrm{h}(\mathrm{Z} \text { 2) }}$ e $\Psi_{\mathrm{h}(\mathrm{Z} \text { o; } 1)}$ são as correções de estabilidade para o transporte de calor a 2,0 $\mathrm{m}$ e 0,1 $\mathrm{m}$, respectivamente.

Diante das correções realizadas no $u^{*}$ e rah retorna-se ao cômputo da função da diferença de temperatura, repetindo-se os cálculos mencionados anteriormente até que se obtenha estabilidade nos valores sucessivos da diferença de temperatura (dT) e da resistência aerodinâmica $\left(\mathrm{r}_{\mathrm{ah}}\right)$. O processo iterativo foi realizado através do $\mathrm{EXCEL}$, mediante uma planilha com equações matemáticas utilizadas na realização das correções dos valores de a e b (constantes de calibração da diferença de temperatura dT) em cada procedimento. Esse método foi necessário para alimentação dos modelos realizados através da ferramenta Model Maker do software ERDAS, sendo usados no cômputo da resistência aerodinâmica corrigida e na velocidade de fricção do vento corrigida em cada iteração, finalizando até que as diferenças entre a resistência na última e penúltima iteração resultassem em diferenças inferiores a 0,01\%.

Após a obtenção do LE mencionado na Equação 1, a ET foi calculada com base na fração evaporativa instantânea $\left(F E_{i}\right)$, definida como o fluxo de calor latente dividido pela soma entre o fluxo de calor latente e o fluxo de calor sensível (SHUTTLEWORTH et al., 1989). Diversos estudos apontam que a FE é igual a $\mathrm{FE}_{24 h}$, e que a mesma é relativamente constante em todo o período diurno. Portanto, tem-se a equação: 
$\mathrm{FE}_{\mathrm{i}}=\left(\frac{\mathrm{LE}}{\mathrm{Rn}-\mathrm{G}}\right)=\frac{\mathrm{LE}_{24 \mathrm{~h}}}{\mathrm{Rn}_{24 \mathrm{~h}}}=\mathrm{FE}_{24 \mathrm{~h}}$

$\mathrm{LE}_{24 \mathrm{~h}}$ e Rn24h correspondem aos valores diários dos fluxos supracitados conforme De Bruin e Stricker (2000):

$\mathrm{Rn}_{24 \mathrm{~h}}=(1-$ albedo $) \mathrm{Rs}, 24 \mathrm{~h}$ medida $-110 \tau_{24 \mathrm{~h}}$

Rs, 24h medida é a radiação solar global diária (integral) obtida na estação meteorológica localizada na área em estudo. A transmissividade atmosférica diária (-) $\tau_{24 h}$ foi calculada conforme (ALLEN et al., 1998):

$\tau_{24 h}=\mathrm{Rs}, 24 \mathrm{~h}$ medida $/ \mathrm{RTOA}_{24 \mathrm{~h}}$

RTOA,24h é a radiação solar incidente no topo da atmosfera, sendo calculada a partir da latitude da estação e do número sequencial do ano. Diante destes dados foi possível realizar a conversão da $\mathrm{LE}_{24 \mathrm{~h}} \mathrm{em} \mathrm{ET}_{24 \mathrm{~h}}\left(\mathrm{~mm} \mathrm{~d}^{-1}\right)$, conforme:

$\mathrm{ET}_{24 \mathrm{~h}}=\mathrm{LE}_{24 \mathrm{~h}} \cdot 86,4 / 2450$

\section{Análise estatística}

Os métodos apresentados na determinação dos componentes do balanço de energia e estimativa da evapotranspiração foram avaliados segundo estatística descritiva dos principais momentos estatísticos no nível diário, além da raiz do erro quadrático médio (RMSE), o erro absoluto médio (EAM), e o erro relativo médio (ERM):

$$
\begin{aligned}
& \text { RMSE }=\left|\frac{\sum_{i=1}^{s}\left(\mathrm{P}_{\mathrm{i}}-0_{\mathrm{i}}\right)^{2}}{0_{\mathrm{i}}}\right|^{\frac{\pi}{2}} \\
& \mathrm{EAM}=\frac{1}{\mathrm{n}} \sum_{\mathrm{i}=1}^{n}\left|\mathrm{P}_{\mathrm{i}}-00_{\mathrm{i}}\right| \\
& \mathrm{ERM}=\frac{100}{\mathrm{n}} \sum_{\mathrm{i}=1}^{n}\left|\frac{\left(\mathrm{P}_{\mathrm{i}}-0_{\mathrm{i}}\right)}{0_{\mathrm{i}}}\right|
\end{aligned}
$$


onde $P_{i}$ é o valor estimado da evapotranspiração (ET) pelo algoritmo SEBAL, Oi é o valor determinado pelo método para obtenção dos valores diários de evapotranspiração de referência, descrito por Monteith (1965) e adaptado por Allen et al. (1989), conforme equação abaixo.

$$
\text { ETo }=\frac{0,408 \Delta\left(R_{n}-G\right)+\gamma \frac{900}{T+273} u_{2} \Delta e}{\Delta+\gamma\left(1+0,34 u_{2}\right)}
$$

em que, ETo é a evapotranspiração de referência $\left(\mathrm{mm} \mathrm{d}^{-1}\right) ; \Delta=$ tangente à curva de pressão de vapor na saturação $\left(\mathrm{kPa}^{\circ} \mathrm{C}^{-1}\right) ; \mathrm{Rn}=$ Saldo da radiação diário $\left(\mathrm{MJ} \mathrm{m}^{-2} \mathrm{~d}^{-}\right.$ $\left.{ }^{1}\right) ; G=$ fluxo de calor no solo $\left(\mathrm{MJ} \mathrm{m}^{-2} \mathrm{~d}^{-1}\right) ; \mathrm{y}=$ constante psicrométrica $\left(\mathrm{kPa}^{\circ} \mathrm{C}^{-1}\right) ; \mathrm{u} 2$ = velocidade do vento a $2 \mathrm{~m}$ de altura $\left(\mathrm{m} \mathrm{s}^{-1}\right)$; es = pressão de saturação do vapor d' água, $(\mathrm{kPa})$; ea = pressão atual de vapor média diária, $(\mathrm{kPa})$ e $\mathrm{T}_{\mathrm{med}}=$ temperatura média do ar diária, obtida em função da temperatura máxima e mínima $\left({ }^{\circ} \mathrm{C}\right)$.

\section{Resultados e discussão}

A Tabela 3 apresenta os resultados de ET24h encontrados nessa pesquisa mediante estimativa SEBAL que foram confrontados com os valores medidos no pixel da torre meteorológica pelo método FAO (Evapotranspiração de referência) assim como os respectivos erros estatísticos.

Tabela 3. Valores estimados através do SEBAL e medidos FAO (evapotranspiração de referência) para os dias sequenciais do ano (DSA) de estudo e seus respectivos erros absoluto $\left(E A, \mathrm{~mm} \mathrm{~d}^{-1}\right)$, relativo $(E R, \%)$ e a raiz do erro quadrático $\left(R E Q, \mathrm{~mm} \mathrm{~d}^{-}\right.$ 1).

\begin{tabular}{ccccccc}
\hline Data & DAS & ET $_{24 \mathbf{4}}$ SEBAL & ET $_{\text {24h }} \mathbf{F A O}$ & EA & ER & REQ \\
\hline $26 / 09 / 2000$ & 269 & 4,22 & 5,24 & 1,02 & 24,17 & 1,04 \\
$26 / 08 / 2006$ & 238 & 3,36 & 4,59 & 1,23 & 36,60 & 1,51 \\
$06 / 09 / 2010$ & 249 & 4,76 & 4,94 & 0,18 & 3,78 & 0,03 \\
$25 / 09 / 2011$ & 268 & 3,82 & 4,85 & 1,03 & 26,96 & 1,06 \\
& & & Média & 0,86 & 22,87 & 0,91 \\
\hline
\end{tabular}

Conforme valores apresentados na tabela supracitada, constatou-se entre os dados, o erro relativo médio de $22,87 \%$, com mínimo erro de $3,78 \%$ e o máximo de $36,60 \%$. Os erros absolutos apresentaram 0,18 e 1,23 mm d-1 mínimo e máximo 
respectivamente, com média de $0,86 \mathrm{~mm} \mathrm{~d}^{-1}$. Em geral, assegura-se uma boa proximidade dos valores com erros baixos, assemelhando-se com os resultados encontrados por (BEZERRA et al., 2008) quando compararam medidas lisimétricas com os resultados do SEBAL, os erros absolutos encontrados foram inferiores a 1,0 $\mathrm{mm} \mathrm{d}^{-1}$. Machado et al. (2012), comparando a ETr medida pelo método FAO-Penman-Monteith com a estimada pelo SEBAL em uma região com remanescente de Mata Atlântica obtiveram $0,5 \mathrm{~mm} \mathrm{~d}^{-1}$ de erro absoluto e 10,8 \% de erro relativo em setembro de 2010 , $0,06 \mathrm{~mm} \mathrm{~d}^{-1}$ de erro absoluto e 1,43\% de erro relativo em agosto de 2006 .

Trezza (2002), após comparar medidas lisimétricas e as estimativas do SEBAL aplicado em sete imagens compreendida entre os anos de 1989 e 1991 no estado americano de Idaho, detectou erros absolutos inferiores a $1 \mathrm{~mm} \mathrm{~d}^{-1}$. Wang et al. (2005) através do referido modelo integrado com imagens MODIS e Landsat 5 aplicados na bacia do rio Hai na China, obtiveram resultados ainda mais satisfatórios, com erros absolutos em torno de $0,5 \mathrm{~mm} \mathrm{~d}^{-1}$, enquanto Bezerra et al. (2008) encontraram erros relativos entre 4 e 10\% quando compararam os resultados obtidos através da razão de Bowen e SEBAL em cultura de mamona e algodão na mesorregião do Cariri, situado no estado da Paraíba.

Conforme os resultados obtidos através dos autores supracitados em análises comparativas da evapotranspiração estimada pelo SEBAL e calculada na estação meteorológica, os resultados obtidos nesta pesquisa foram coerentes em margem de erros. Entretanto, o trabalho em análise objetivou a mensuração das taxas evapotranspirativas liberado nas feições de vegetação e corpos hídricos como contribuição ao clima urbano. Sendo assim, para tal feito não foi necessário usar culturas irrigadas como referência na validação da carta de evapotranspiração, comumente usados em estudos de agricultura de precisão através da mensuração do Kc (coeficiente de cultura).

A Figura 4 apresenta as médias e desvio padrão da evapotranspiração diária entre as datas 269/2000, 238/2006, 249/2010 e 268/2011, respectivamente, estimadas SEBAL. O maior valor da média apresentado entre as datas correspondeu a $5,08 \mathrm{~mm} \mathrm{~d}^{-1}$ e com desvio entre 3,8 e $6,02 \mathrm{~mm} \mathrm{~d}^{-1}$ para 0 dia 249/2010, enquanto a menor média encontrada foi de $3,86 \mathrm{~mm} \mathrm{~d}^{-1} \mathrm{em} \mathrm{268/2011} \mathrm{com}$ a maior variação entre os valores, entre 2,2 e 4,9 $\mathrm{mm} \mathrm{d}^{-1}$. Atribui-se a essa variação ao baixo percentual de coberturas naturais propensas à evaporação em relação ao alto percentual de superfícies impermeáveis com propriedades absorvedoras de calor. 


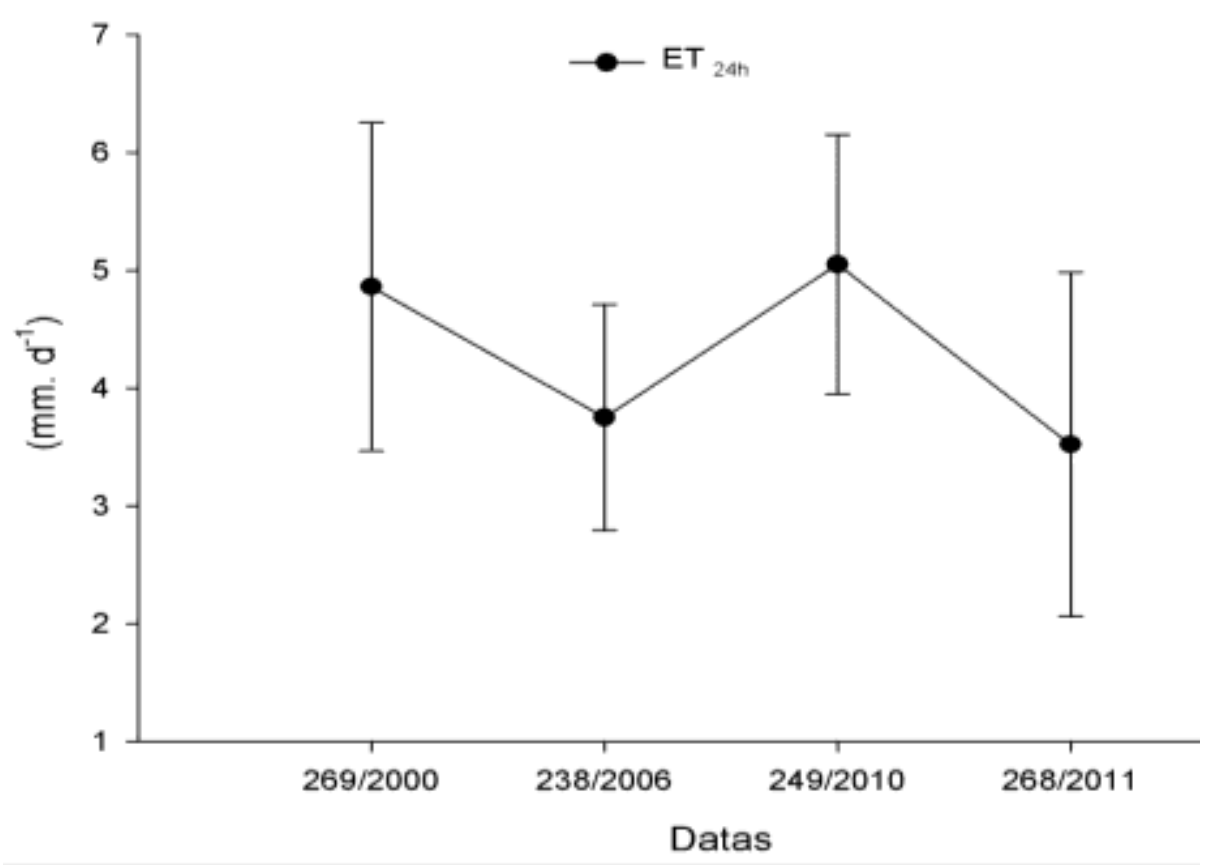

Figura 4. Valores médios e desvio padrão da evapotranspiração diária em 269/2000, 238/2006, 249/2010 e 268/2011.

A média apresentada no dia $269 / 2000$ foi de $4,83 \mathrm{~mm} \mathrm{~d}^{-1}$ e com desvio padrão entre 6,2 e $3,5 \mathrm{~mm} \mathrm{~d}^{-1}$, valores com intensidade aproximados aos apresentados na data anterior, sendo a data 238/2006 com média 3,8 $\mathrm{mm} \mathrm{d}^{-1}$ e com menor desvio padrão, 2,7 e 4,8 $\mathrm{mm} \mathrm{d}^{-1}$. O desvio padrão apresentou variação alta entre os valores analisados, seguindo o mesmo padrão para parâmetros físicos estimados em superfícies com resposta espectrais diferenciadas, fato explicado para os diferentes tipos de coberturas presentes na área em estudo.

A Figura 5 apresenta a dinâmica temporal da variabilidade espacial para evapotranspiração diária estimadas mediante o algoritmo SEBAL. Foi possível constatar nas feições da superfície desprovida de vegetação e com solos impermeáveis valores de $\mathrm{ET}_{24 \mathrm{~h}}$ inferior a $1,00 \mathrm{~mm} \mathrm{~d}^{-1}$, representados pela classe de tonalidade vermelha, destacando-se com maior intensidade na cena de 268/2011, coadunando com o baixo percentual do fluxo de calor latente registrado na data. Gomes et al. (2013) encontraram 0,09 $\mathrm{mm} \mathrm{d}^{-1}$ na área urbana de Patos (PB) e valores próximos de $9,00 \mathrm{~mm} \mathrm{~d}^{-1}$ em matas ciliares. 

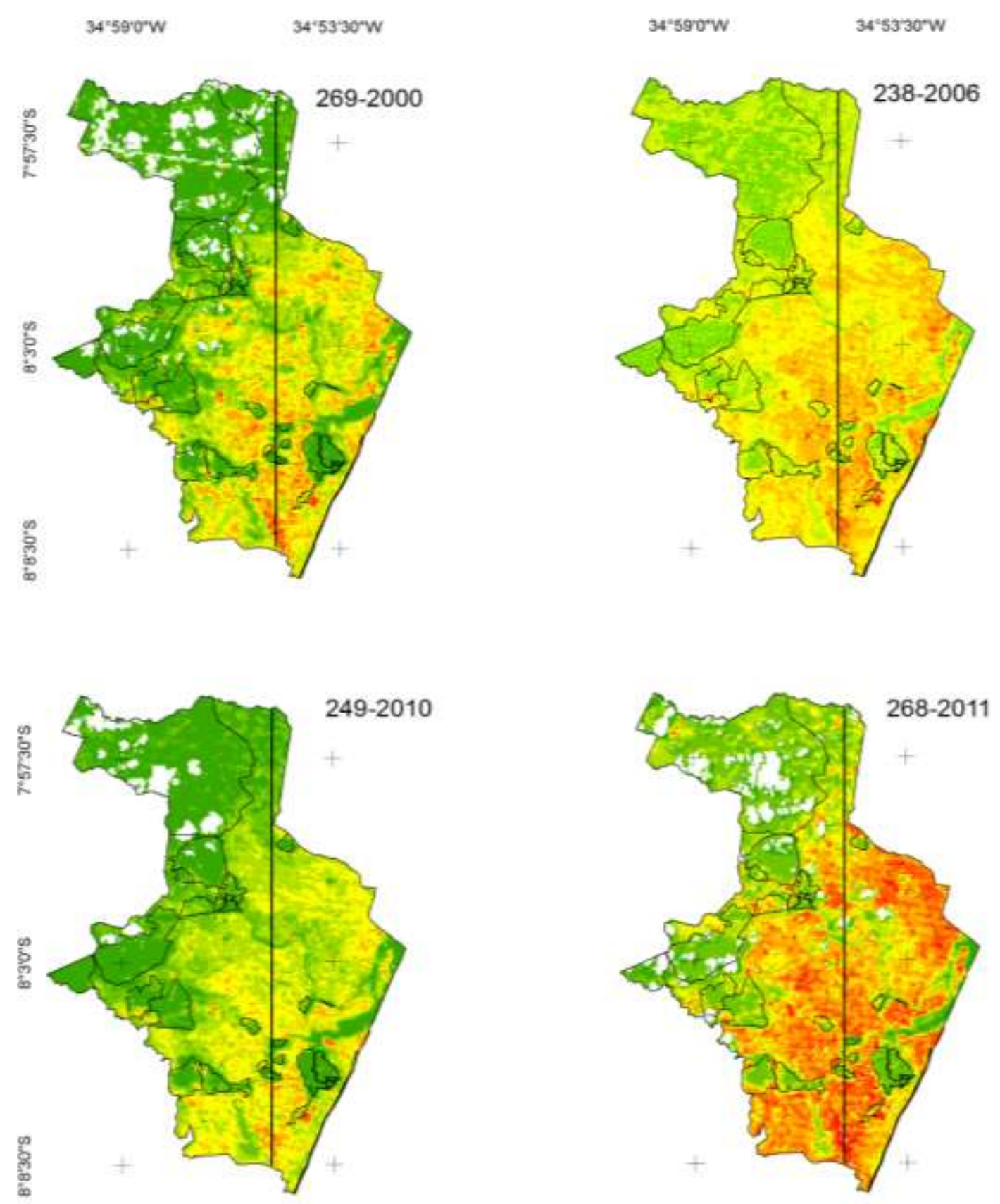

$34 \cdot 5907 \mathrm{~W}$

$34^{*} 53^{3} 30^{7} \mathrm{~W}$

34 390rW

$34^{-53} 30^{*} \mathrm{~W}$

Evapotranspiração $24 \mathrm{~h}\left(\mathrm{~mm} \mathrm{~d}^{-1}\right)$
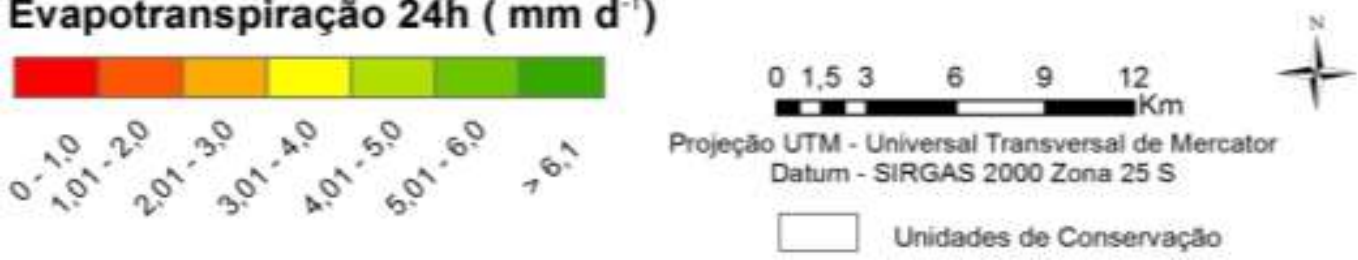

Figura 5. Carta temática da distribuição espacial da evapotranspiração diária nas datas 269-2000, 238-2006, 249-2010 e 268-2011.

Foi possível constatar nas feições da superfície desprovida de vegetação e com solos impermeáveis valores de $\mathrm{ET}_{24 \mathrm{~h}}$ inferior a $1,00 \mathrm{~mm} \mathrm{~d}^{-1}$, representados pela classe de tonalidade vermelha destacando-se com maior intensidade na cena de 
268/2011, coadunando com o baixo percentual do fluxo de calor latente registrado na data.

As áreas providas de vegetação e corpos hídricos representadas na tonalidade verde, apresentaram os maiores valores de $\mathrm{ET}_{24 \mathrm{~h}}$, com intervalos de 6,01 $\mathrm{mm} \mathrm{d}^{-1}$. Essas feições proporcionam em escala local o aumento de umidade e a redução da temperatura do ar, podendo assim, favorecer o surgimento das ilhas de amenidade. As áreas destacadas na tonalidade amarela, apresentaram intervalos oscilando entre 3,01 e 4,00 $\mathrm{mm} \mathrm{d}^{-1}$ e, com distribuição mais homogênea na porção leste de todas as cenas, com os menores valores de $\mathrm{ET}_{24 \mathrm{~h}}$. A baixa magnitude dos valores nessa área contribui na formação de zonas quentes, proporcionando com isto o predomínio da conversão da energia para o aquecimento da superfície.

Uda et al. (2013) analisaram a evapotranspiração real diária de diferentes usos e coberturas do solo da bacia do rio Negrinho (SC), através do modelo SEBAL e imagens ASTER. Os resultados encontrados apresentaram a menor taxa de evapotranspiração nas áreas que correspondem à intensa interferência antrópica (áreas urbanas e solo exposto), com valores entre 0,0 a 2,7 $\mathrm{mm} \mathrm{d}^{-1}$, enquanto nas feições com vegetação densa e corpos hídricos representaram os maiores percentuais, destacando intervalos entre 4 a $5,3 \mathrm{~mm} \mathrm{~d}^{-1}$. Fazendo uso do mesmo modelo com imagens Landsat 5, (LIU et al., 2010), estimaram a evapotranspiração na área urbana de Oklahoma e avaliaram a variação espacial nos diferentes tipos de coberturas. Os autores encontraram valores inferiores a 1,0 $\mathrm{mm}$ nas áreas mais desenvolvidas e 7,53 mm em corpos hídricos como lagos e rios, e com média diária de 3,28 mm em toda área de estudo.

Em todas as cenas analisadas os arranjos espaciais modularam a distribuição dos valores conforme os diferentes tipos de feições. Os baixos valores de $\mathrm{ET}_{24 \mathrm{~h}}$ foram influenciados nas regiões de intenso adensamento construtivo, sendo resultante da reduzida cobertura de vegetação e, consequentemente, alterações no espaço urbano, promovendo oscilações importantes nos elementos climáticos direcionados ao balanço de energia e incremento nos valores de temperatura do ar.

Analisando a percentagem de pixels em cada classe da ET24h (Tabela 4), constata-se a classe ET > 6,01 $\mathrm{mm} \mathrm{d}^{-1}$ com maior representatividade nas datas 269/2000 e 269/2010, correspondendo a $31,80 \%$ e 30,66 \%, respectivamente, enquanto a data 238/2006 não houve percentual representativo. As classes ET < 1,00 e $(5,01<\mathrm{ET}<6,00)$ representaram os maiores percentuais na data 268/2011, $21,44 \%$. 
Tabela 4. Distribuição percentual das classes da evapotranspiração $24 \mathrm{~h}$ nas datas em análise.

\begin{tabular}{crrrr}
\hline ET 24h $\left(\mathbf{m m ~ d}^{-1}\right)$ & $\mathbf{2 6 9 / 2 0 0 0}$ & $\mathbf{2 3 8 / 2 0 0 6}$ & $\mathbf{2 4 9 / 2 0 1 0}$ & $\mathbf{2 6 8 / 2 0 1 1}$ \\
\hline ET $<1,00$ & $0,24 \%$ & $0,23 \%$ & $0,05 \%$ & $1,53 \%$ \\
$1,01<\mathrm{ET}<2,00$ & $1,20 \%$ & $2,52 \%$ & $0,36 \%$ & $12,87 \%$ \\
$2,01<\mathrm{ET}<3,00$ & $9,83 \%$ & $21,97 \%$ & $3,59 \%$ & $25,37 \%$ \\
$3,01<\mathrm{ET}<4,00$ & $20,80 \%$ & $28,28 \%$ & $19,93 \%$ & $16,14 \%$ \\
$4,01<\mathrm{ET}<5,00$ & $18,15 \%$ & $28,42 \%$ & $26,15 \%$ & $17,89 \%$ \\
$5,01<\mathrm{ET}<6,00$ & $17,98 \%$ & $18,58 \%$ & $19,26 \%$ & $21,44 \%$ \\
$\mathrm{ET}>6,01$ & $31,80 \%$ & $0 \%$ & $30,66 \%$ & $4,73 \%$ \\
\hline
\end{tabular}

A Figura 6 apresenta o perfil norte-sul da evapotranspiração relacionada com o tipo de cobertura do solo dentro da malha urbana. $O$ transecto delimitado, tem início no eixo Norte (zero) e estende-se ao Sul da cidade em uma distância de aproximadamente $22.500 \mathrm{~m}$, correspondendo a 752 dados nos anos 2000 (a), 2006 (b), 2010 (c) e 2011(d), respectivamente.

Os perfis apresentaram os maiores valores no eixo norte entre as distâncias 0 - 5.000 m, onde há um predomínio de áreas com alto percentual de vegetação, destacando-se a mata da Guabiraba em maior representação espacial com evapotranspiração superior a $6,0 \mathrm{~mm} \mathrm{~d}^{-1}$ aproximadamente. As distâncias entre 5.000 e $10.000 \mathrm{~m}$, apontam para uma mudança na configuração do uso no solo, sendo demarcada pela predominância da urbanização com os diferentes tipos de materiais construtivos, refletindo em padrão de declínio com valores inferiores a 6,0 $\mathrm{mm} \mathrm{d}^{-1}$.

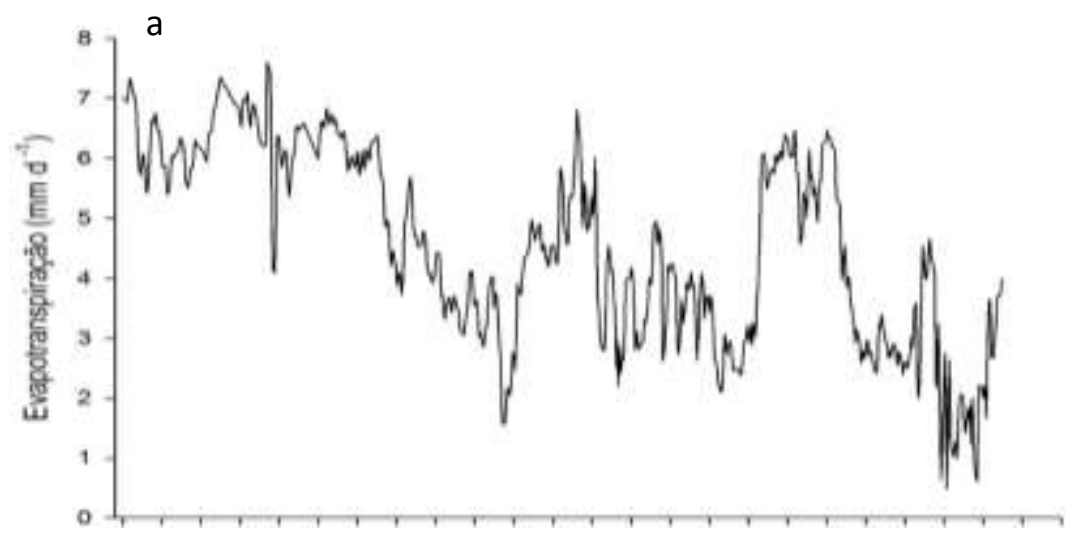



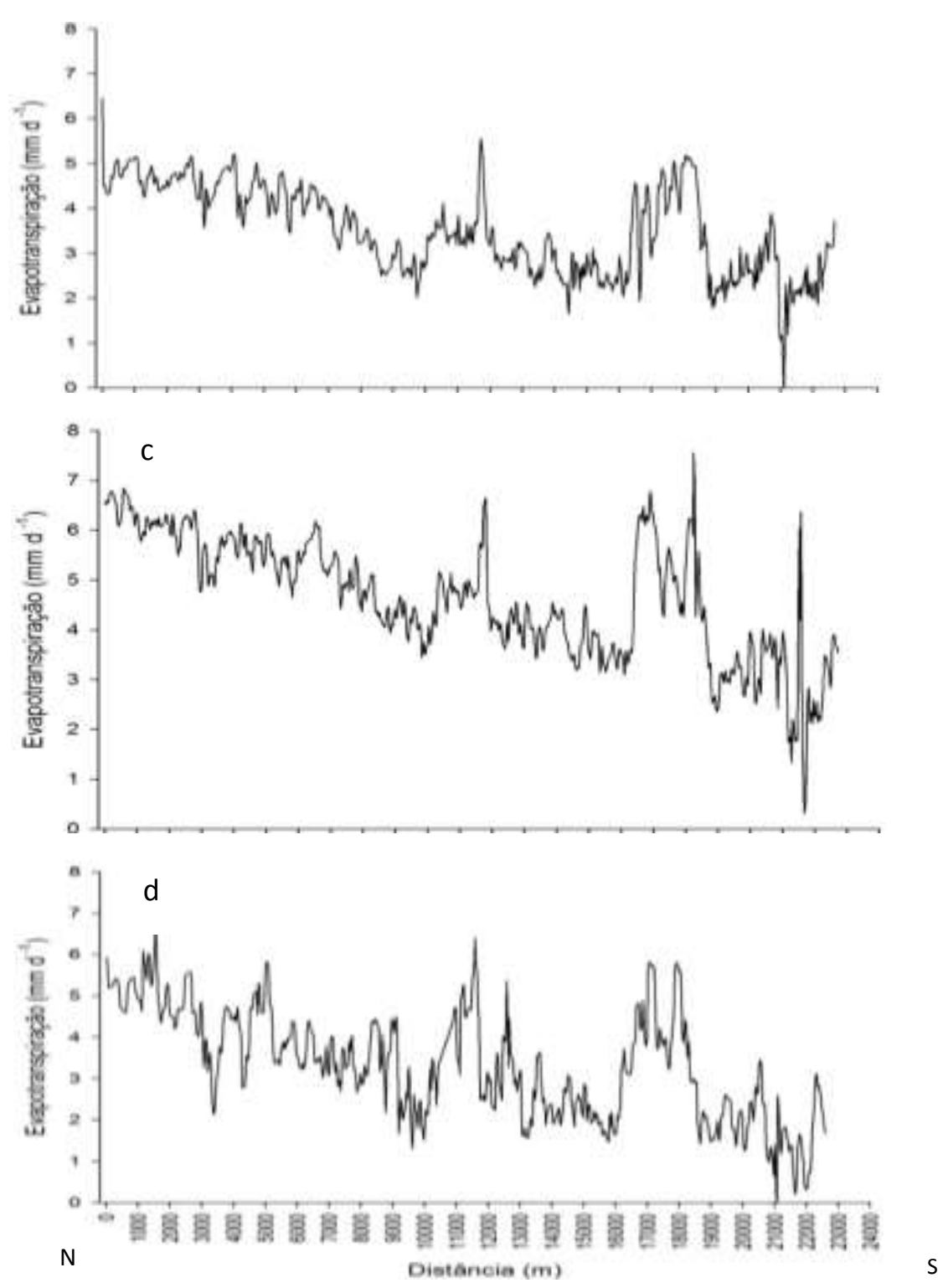

Figura 6. Perfil norte-Sul da evapotranspiração representado no transecto com distância 0 - 22.500 m, para os anos de 2000 (a), 2006 (b), 2010 (c) e 2011 (d), respectivamente.

A Figura 7 representa a relação entre o NDVI e ET 24h para cinco alvos selecionados nas feições de mata atlântica e fragmentos de mangue, referente à data 268/2011. Os alvos elucidam alto potencial evapotranspirativo, destacando a Mata do Ibura e Mata do Engenho Uchoa com ET $24 \mathrm{~h}$ aproximadamente 6,2 $\mathrm{mm} \mathrm{d}^{-1}$ e $5,8 \mathrm{~mm} \mathrm{~d}^{-1}$, com NDVI entre 0,75 e 0,73 , respectivamente. O manguezal apresentou valores de $\mathrm{ET}_{24 \mathrm{~h}}$ aproximadamente $3,85 \mathrm{~mm} \mathrm{~d}^{-1}$ e com NDVI 0,69, valores de $\mathrm{ET}_{24 \mathrm{~h}}$ entre $4,5 \mathrm{~mm} \mathrm{~d}^{-1}$ e com NDVI 0,71 foi encontrado na Reserva Ecológica Dois Unidos, sendo a Reserva Dois Irmãos com valores de ET 24h 5,0 mm $\mathrm{d}^{-1}$ e NDVI 0,72 . 


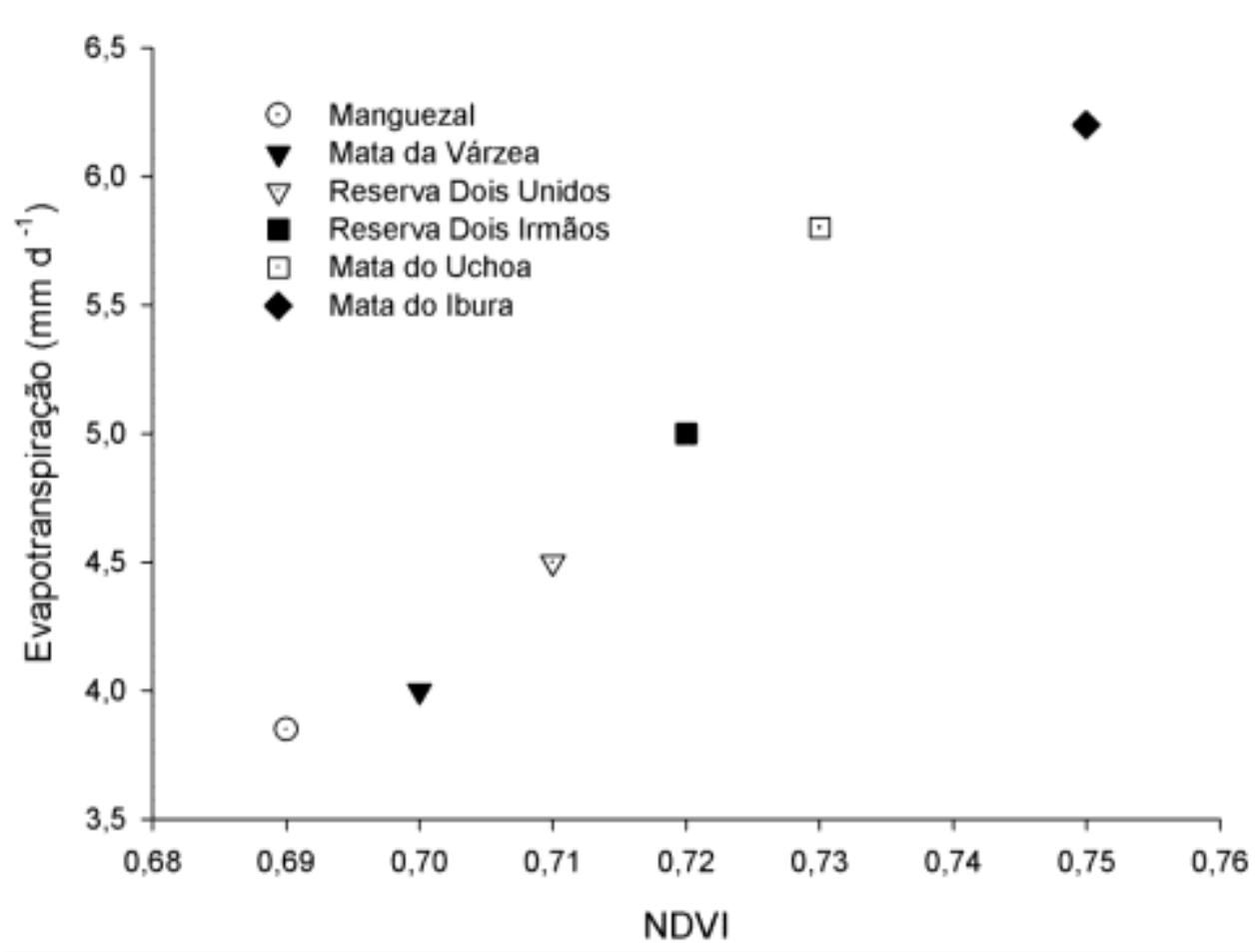

Figura 7. Relação estatística entre evapotranspiração diária e o índice de vegetação NDVI nos alvos: Mata da Várzea, Manguezal do Pina, Mata do lbura, Reserva Dois Irmãos, Reserva Dois Unidos e Mata do Uchoa em 268/2011.

Constatou-se que nos alvos com valores de NDVI superiores a 0,69, uma forte relação com $\mathrm{ET}_{24 \mathrm{~h}}$, apontando com isto a relevância evaporativa das áreas verdes no ambiente urbano e sua contribuição no clima em escala local, em detrimento da expansão construtiva destacado nas coberturas impermeáveis da cidade.

\section{Considerações Finais}

A estimativa da evapotranspiração através de imagens digitais do sensor TM Landsat 5 implementados no algoritmo SEBAL, representou de forma coerente os diferentes tipos de superfícies, destacando em todas as cenas analisadas os maiores valores nas unidades de conservação e corpos hídricos representados nas classes entre 5,0 e 6,2 mm d-1, aproximadamente. Essas feições promovem o arrefecimento da temperatura, enquanto as superfícies com intensos adensamentos construtivos apresentaram valores próximos de $1,0 \mathrm{~mm} \mathrm{~d} \mathrm{~d}^{-1}$. As feições representadas no Shopping Recife e o Aeroporto elucidaram valores de ET 24h inferiores a $1,0 \mathrm{~mm} \mathrm{~d}^{-1}$, representando alvos propensos ao armazenamento de radiação empregados no aquecimento da superfície e aumento na temperatura do ar. 
O baixo percentual de evapotranspiração constatado na maior parte da área em estudo aponta para o intenso uso do espaço geográfico de forma não planejada, induzindo reflexos na qualidade de vida da população, demarcado por zonas quentes em detrimento de áreas produtoras de umidade. Sendo assim, informações desta magnitude poderão servir como subsídios nas práticas e tomadas de decisão dos órgãos competentes no planejamento urbano, visando melhorar as condições microclimáticas e à mitigação de ambientes climaticamente confortáveis inseridas nos arranjos espaciais da cidade.

\section{REFERÊNCIAS}

ALLEN, R.G.; JENSEN, M.E.; BORNAN, R. D. Operational estimates of reference evapotranspiration. Agronomy Journal, Madison, v.81, n. 4, p.650-662, 1989.

ALLEN, R. G.; PEREIRA, L. S.; SMITH, M. Crop Evapotranspiration - Guidelines for Computing Crop Water Requirements. FAO Irrigation and Drainage Paper, No. 56, FAO. Rome, Italy, 318 p. 1998.

ALLEN, R. G.; TASUMI, M.; TREZZA, R. SEBAL (Surface Energy Balance Algorithms for Land). Advance Training and Users Manual - Idaho Implementation, VERSION 1.0, 97p., 2002.

BASTIAANSSEN, W.G.M.; MENENTI, M.; FEDDES, R. A.; HOLTSLAG, A.A.M.A. Remote Sensing Surface Energy Balance Algorithm for Land (SEBAL) 1. Formulation. Journal of Hydrology, v. 212-213, p. 198-212, 1998.

BASTIAANSSEN, W. G. M. SEBAL - based sensible and latent heat fluxes in the irrigated Gediz Basin, Turkey. Journal of Hydrology, v.229, p.87-100, 2000.

BEZERRA, B. G.; SILVA, B. B.; FERREIRA, N. J. Estimativa da evapotranspiração real diária utilizando-se imagens digitais TM - Landsat 5. Revista Brasileira de Meteorologia, v.23, p. 305-317, 2008.

BEZERRA, M. V. C.; SILVA, B. B.; BEZERRA, B. G. Avaliação dos efeitos atmosféricos no albedo e NDVI obtidos com imagens de satélite. Revista Brasileira de Engenharia Agrícola e Ambiental. Campina Grande, PB. v.15, p. 709-717, 2011.

BRUTSAERT, W. Evaporation Into the Atmosphere: Theory, History and Applications. D. Reidel Pub, Co, 299 p. 1982.

CHANDER, G.; MARKHAM, B. L.; BARSI, J. A. Revised Landsat - 5 Thematic Mapper Radiometric Calibration. IEEE Geoscience and Remote Sensing Letters, v. 4, n. 3, p. 490494, 2007.

CHOUDHURY, B. J. Estimating evaporation and carbon assimilation using infrared temperature data: vistas in modelling. Theory and Applications of Optical Remote Sensing, p.628-690, 1989.

CORREA, A. C. B. Contribuição à análise do Recife como um Geossistema Urbano. Revista de Geografia da UFPE, Vol.23 n.3. p.86-102 Recife: UFPE, 2006. 
DE BRUIN, H. A. R.; STRICKER, J. N. M. Evaporation of grass under non-restricted soil moisture conditions, Hydrology Science Journal, n. 45(2), p. 391-406, 2000.

FILHO, V. P. S.; VISWANADHAM, Y.; SANTOS, J. M. Determinação da constante de vonKarman a partir de dados coletados na Amazônia. Revista Brasileira de Meteorologia, v.7, n.1, p.535-541, 1992.

GOMES, L. C. F.; SANTOS, C. A. C.; ALMEIDA, H. A. Balanço de Energia à Superfície para a Cidade de Patos-PB Usando Técnicas de Sensoriamento Remoto, Revista Brasileira de Geografia Física, v. 6, p.15-28, 2013.

GRIMMOND, C. S. B.; KUTTLER, W.; LINDQVIST, S.; ROTH, M. Urban Climatology ICUC6. International Journal of Climatology, v.27, p.1847-1848, 2007.

LIU, W et al. Actual evapotranspiration estimation for different land use and land cover in urban regions using Landsat 5 data. Journal of Applied Remote Sensing, vol. 4, p.1-14, 2010.

LOMBARDO, M. A. Ilha de calor nas metrópoles: o exemplo de São Paulo. 1 ed. Hucitec, 1985.

MACHADO, C. C. C.; SILVA, B. B. DA.; ALBUQUERQUE, M. B.; GALVÍNCIO, J. D. Evapotranspiração real diária utilizando uma imagem digital TM-Landsat 5 e o algoritmo SEBAL. In anais do Workshop Internacional de Inovações Tecnológicas na Irrigação, p.1-5, 2012.

MEDINA, J. L.; CAMACHO, E.; RECA, J.; LÓPEZ, R.; ROLDÁN, J. Determination and analysis of regional evapotranspiration in Southern Spain based on Remote Sensing and GIS. Physical and Chemistry of the Earth, vol. 23, No. 4, 427-432, 1998.

MENDONÇA, J. C.; SOUSA, E. F.; BOUHID, R. G.; SILVA, B. B.; FERREIRA, N. J. Estimativa do fluxo do calor sensível utilizando o algoritmo sebal e imagens modis para a região norte fluminense, RJ. Revista Brasileira de Meteorologia, v.27, n.1, p. 85- 94, 2012.

MONTEITH, J. L. Evaporation and environment. In G.E. Fogg (ed.) Symposium of the Society for Experimental Biology, The State and Movement of Water in Living Organisms, Vol. 19, Academic Press, Inc., NY. p. 205-234. 1965.

MONTEIRO, C. A. F. Por um Suporte Teórico e Prático para Estimular Estudos Geográficos de Clima Urbano no Brasil. Geosul, ano V, n.9, p.7-19, 1ํ Semestre. 1990.

MONIN, A S.; OBUKHOV, A. M. Dimensionless characteristics of turbulence in the surface layer of the atmosphere, Trudy Akad Nauk SSSR Geophizica, v. 24, p.163-187, 1954.

MOREIRA, E. B. M. Balanço de energia e evapotranspiração na cidade do Recife por sensoriamento remoto. Tese. Universidade Federal de Pernambuco, 155p, 2014.

PAULSON, C. A. The Mathematical Representation of Wind Speed and Temperature Profiles in the Unstable Atmospheric Surface Layer. Journal of Applied Meteorology, v.9, p. 856-861, 1970.

PEREZ, J. C.; SANCHEZ, M. A. V.; BARRADAS, V. L. Clima, urbanización y uso del suelo en ciudades tropicales de Mexico. RNIU, Puebla, México, Ciudades 51. 2001.

PONZONI, F. J.; SHIMABUKURO, Y. E. Sensoriamento remoto no estudo da vegetação. São José dos Campos: Parêntesis, 2007. 136 p. 
KUSTAS, W. P.; NORMAN, J. M. Use of remote sensing for evapotranspiration monitoring over land surfaces. Journal of Hydrology, v. 41, p. 495-516, 1996.

SHUTTLEWORTH, W. J.; GURNEY, R. J.; HSU, A. Y. \& ORMSBY, J. P. FIFE: the variation in energy partition at surface flux sites. IAHS Publ. n. 186, 1989.

SILVA, B. B. da., BEZERRA, M. V. C. Determinação dos fluxos de calor sensível e latente na superfície utilizando imagens TM - Landsat 5. Revista Brasileira de Agrometeorologia, v. 14, n. 2, p. 174-186, 2006.

SILVA, B. B. da., SILVA, S. T. A.; GOMES, H. B. Alterações climáticas decorrentes de mudanças no uso da terra mediante sensoriamento remoto. Revista Mercator, v.9, p. 91106, 2010.

SILVA, B. B da., BRAGA, A. C.; BRAGA, C. C. Balanço de radiação no perímetro irrigado São Gonçalo - PB mediante imagens orbitais. Revista Caatinga, v.24, n.3, p.145-152, 2011.

TASUMI, M. Progress in operational estimation of regional evapotranspiration using satellite imagery. Dissertation presented at The University of Idaho, USA. 357 p, 2003.

TEIXEIRA, A. H. C.; W.G.M., BASTIAANSSEN, AHMAD, M-UD-D, BOS, M. G. Reviewing SEBAL input parameters for assessing evapotranspiration and water productivity for the Low-Middle São Francisco River basin, Brazil Part A: Calibration and validation. Agricultural and Forest Meteorology, v.149, p.462-476, 2009a.

TEIXEIRA, A. H. C.; W.G.M., BASTIAANSSEN, AHMAD, M-UD-D, BOS, M. G. Reviewing SEBAL input parameters for assessing evapotranspiration and water productivity for the Low-Middle São Francisco River basin, Brazil Part B: Application to the large scale.

Agricultural and Forest Meteorology, v.149, p.477- 490, 2009b.

TIMMERMANS, J. W.; JIMÉNEZ-MUNÕZ, J. C.; HIDALGO, V.; RICHTER, K.; SOBRINHO, J. A. Estimation of the spatially distributed surface energy budget for AgriSAR 2006, part I: remote sensing model intercomparison. leee Journal of Selected Topics in Applied Earth Observations and Remote Sensing, v.4, p.465-481, 2011.

TREZZA, R. Evapotranspiration using a satellite-based surface energy balance with standardized ground control. Ph.D. dissertation, Utah State University., Logan, Utah, 247p. 2002.

UDA, P. K.; CORSEUIL, C. W.; KOBIYAMA, M.; SILVA, F. V. Análise da evapotranspiração real diária para diferentes usos e coberturas do solo da bacia do rio Negrinho - SC por meio do modelo SEBAL e imagens ASTER. In anais... Simpósio Brasileiro de Sensoriamento Remoto, p. 323-332, 2013.

WANG, J., T.W.; SAMMIS, C.A.; MEIER, L.J.; SIMMONS, D.R.; MILLER, AND Z. SAMANI. A modified SEBAL model for spatially estimating pecan consumptive water use for Las Cruces, New Mexico. 15th Conference on Applied Climatology. Hilton Savannah Desoto, Savannah, Georgia. 20-24, June, 2005.

WEBB, E. K. Profile Relationships: the Log-linear Range and Extension to Strong Stability. Quartely Journal of the Royal Meteorological Society, v. 96 p. 67-90, 1970. 


\section{NOTAS DE AUTOR}

\section{CONTRIBUIÇÃO DE AUTORIA}

Elvis Bergue Mariz Moreira - Aquisição dos dados orbitais, processamento, análise e interpretação. Ranyére Silva Nóbrega - Participação ativa na redação e discussão do resultados.

Bernardo Barbosa da Silva - Revisão e aprovação da versão final do trabalho.

Eberson Pessoa Ribeiro - Responsável pela tradução, design e revisão do texto

\section{FINANCIAMENTO}

Coordenação de Aperfeiçoamento de Pessoal de Nível Superior - CAPES

\section{CONSENTIMENTO DE USO DE IMAGEM}

Não se aplica

APROVAÇÃO DE COMITÊ DE ÉTICA EM PESQUISA

Não se aplica

\section{CONFLITO DE INTERESSES}

Não se aplica

\section{LICENÇA DE USO}

Este artigo está licenciado sob a Licença Creative Commons CC-BY. Com essa licença você pode compartilhar, adaptar, criar para qualquer fim, desde que atribua a autoria da obra.

\section{HISTÓRICO}

Recebido em: 22-10-2015

Aprovado em: 03-01-2019 